\title{
Peptic Ulcer Disease in CHUYO
}

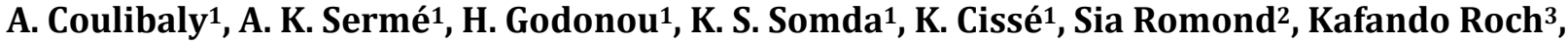 R. A. Sombié1, A. Bougouma ${ }^{1}$}

${ }^{1}$ Gastroenterology Service of the University Hospital Centre Yalgado Ouédraogo (CHUYO), Ouagadougou, Burkina Faso

${ }^{2}$ Schipphra Medical Center, Ouagadougou, Burkina Faso

${ }^{3}$ Surgery of CHUYO, Ouagadougou, Burkina Faso

Email: coulibacar@yahoo.fr

How to cite this paper: Coulibaly, A., Sermé, A.K., Godonou, H., Somda, K.S., Cissé, K., Romond, S., Roch, K., Sombié, R.A. and Bougouma, A. (2016) Peptic Ulcer Disease in CHUYO. Open Journal of Gastroenterology, 6, 353-361.

http://dx.doi.org/10.4236/ojgas.2016.611038

Received: September 28, 2016

Accepted: November 26, 2016

Published: November 29, 2016

Copyright $\odot 2016$ by authors and Scientific Research Publishing Inc. This work is licensed under the Creative Commons Attribution International License (CC BY 4.0).

http://creativecommons.org/licenses/by/4.0/

\begin{abstract}
Background: Prevalence of Peptic Ulcer Disease (PUD) is decreasing in developed countries since the use of the treatments for eradication of Helicobacter pylori. Objectives: To revalue the sociodemographic, clinical and evolutionary aspects of the PUD among hospitalized patients in CHUYO. Methodology: This prospective study is related to 65 files of patients hospitalized in hepato-gastroenterology and general surgical services of the CHUYO between March 1st and August 31st, 2015. Results: Hospital utilization rate was $6.59 \%$. The average age of patients was 40.6 years with extremes of 17 and 80 years. The sex ratio was 9.8. The location of the ulcer was $69.23 \%$ in stomach. A notion of taking aggressive gastrointestinal products was found in 62 patients (95.4\%). The clinical picture was represented by diffuse abdominal pain $(76.92 \%)$, peritoneal irritation syndrome $(64.61 \%)$ and epigastric pain (56.92\%), anemia (23.07\%). Gastric perforations (64.61\%) and gastrointestinal bleeding $(12.30 \%)$ were the main complications. Consumption of non-steroidal anti-inflammatory drugs (NSAIDs) was found in $81.5 \%$ of cases. The management was medical and/or surgical with an overall mortality rate of $7.7 \%$. Conclusion: The PUD rate decreased from $10.12 \%$ to $6.59 \%$ in 5 years. The complications are dominated by stomach perforations. They are relative increase and seem related to NSAIDs. Better management of this disease requires awareness of the population to selfmedication.
\end{abstract}

\section{Keywords}

Peptic Ulcer Disease, Helicobacter pylori, Bleeding Perforation

\section{Introduction}

The Peptic Ulcer Disease (PUD) is a universal affection affecting about eight to ten percent people in Occident. It is a public health problem because of its prevalence, the 
risk of complications and socioeconomic impact (absenteeism, high cost of the explorations and treatments). Studies led in Australia and in Great Britain gave prevalence between $5.2 \%$ and $9.9 \%$ in the general population [1]. In Black Africa, since the introduction of endoscopy (1980), more and more publications show that this disease occupies a significant place in the pathology of the black African. In Mali, Togo and Congo the prevalence of the Peptic Ulcer Disease (PUD) was respectively $10.88 \%, 15.53 \%$ and $30.42 \%$ [2] [3] [4].

The advent of potent inhibitors of gastric secretion and eradication of Helicobacter pylori has revolutionized the treatment of peptic ulcer disease (PUD) [1] [2] [3]. This advanced therapy has resulted in the decrease in the frequency of this pathology and therefore its hospitalizations worldwide [2] [4] [5]. In Africa, despite the progress, the treatment of PUD remains a challenge in most countries because of the low socioeconomic level of the population.

In Burkina Faso, an earlier study conducted in 2010 on the gastroduodenal ulcer prevalence reported his hospitalization rate to $10.12 \%$ [6].

The purpose of this study was to reassess the sociodemographic, clinical and evolutionary aspects of peptic ulcer disease in hospital at the University Hospital Yalgado Ouédraogo.

\section{Patients and Methods}

A prospective and cross-sectional study was conducted among patients hospitalized in the period from 01 March to 31 August 2015 or 6 months in the service of HepatoGastroenterology (HGE) and General and Digestive Surgery (CGD). The diagnosis of peptic ulcer disease was selected based on the results of gastroscopy and/or surgery.

Inclusion criteria: All patients, of all sexes, and hospitalized with a clinical case in which the diagnosis of peptic ulcer disease has been retained on the records of gastroscopy and/or surgery.

The selection of the study population was made from an interview and physical examination. The studied variables were sociodemographic data, personal history, clinical and laboratory data, treatment history, and evolutionary aspects.

The socioeconomic level was evaluated based on means of transportation into three levels: low (walking, bicycle), medium (motorbike) and high (personal vehicle).

Data were analyzed using software Epi-info 3.5.4 of the French version and Excel 2007.

\section{Results}

Sixty-five cases of patients with PUD in both services were found during the study period among 986 patients. In total the PUD rate was 6.59\%. The frequency of the PUD was $12.23 \%$ in the HGE Service (23 cases out of 188 ) and $5.26 \%$ by CGD ( 42 cases out of 798).

\subsection{Sociodemographic Factors}

Age and sex of patients 
Ages ranged between 17 and 80 years with a mean of 40.6 years ( 42.4 years for Duedonal Ulcer and 40.29 for Gastric Ulcer).

There were 59 men $(90.8 \%)$ and 6 women (9.2\%) as a sex ratio of 9.8 .

Figure 1 shows the distribution of patients by age and sex slice.

\subsection{Socioeconomic Level and Living}

The distribution of patients by socio-economic level and origin is summarized in Table 1.

\subsection{Clinical Aspects}

\section{Antecedents}

Table 2 showed antecedents of patients according to the location of the PUD.

Thirteen persons (20\%) were already been treated by anti-ulcer treatment. This treatment was essentially based on inhibitors of proton pump.

The main clinical signs depending on the location were represented in Table 3.

Different clinical forms of PUD are shown in Table 4.

The site of perforation was gastric (anterior antrum) in $95.2 \%$ and $4.8 \%$ was duodenal.

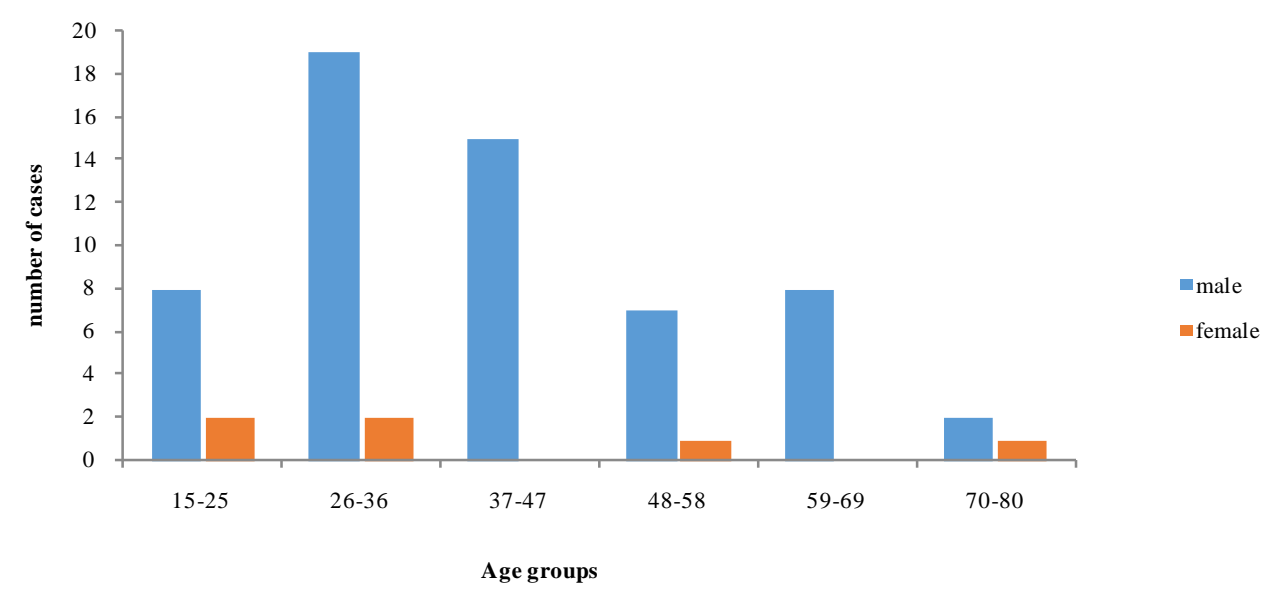

Figure 1. Distribution of patients by age and sex slices.

Table 1. Distribution of patients by socio-economic level and origin.

\begin{tabular}{ccc}
\hline & Frequency & Percentage \\
\hline Socioeconomic level & 49 & 75.4 \\
Average & 14 & 21.5 \\
Low & 2 & 3.1 \\
high & & \\
Living & 27 & 41.5 \\
Urban & 25 & 38.5 \\
Rural & 13 & 20 \\
Semi urban &
\end{tabular}


Table 2. Antecedents of patients according to the location of the PUD.

\begin{tabular}{cccc}
\hline Antecedents & UG & UD & UGD \\
\hline Epigastralgia & 30 & 13 & $43(66 \%)$ \\
PUD & 0 & 2 & $2(3.07 \%)$ \\
NSAIDs & 38 & 15 & $53(81.5 \%)$ \\
Alcohol & 22 & 10 & $32(49.2 \%)$ \\
Tobacco & 23 & 10 & $33(50.8 \%)$ \\
Spices & 20 & 9 & $29(44.6 \%)$ \\
Treatment antiulcer & 5 & 8 & $13(20 \%)$ \\
\hline
\end{tabular}

UG: Gastric Ulcer; UD: Duodenal perforation; UGD: Gastro Duodenal Ulcer.

Table 3. Main symptoms depending on the location of the MUGD.

\begin{tabular}{cccc}
\hline Clinical signs & U.G & U.D & UGD \\
\hline Peritoneal irritation & 40 & 2 & $42(64.6 \%)$ \\
Epigastralgia & 35 & 12 & $37(56.9 \%)$ \\
Diffuse abdominal pain & 40 & 10 & $50(76.9 \%)$ \\
Hematemesis/melena & 2 & 6 & $8(12.30 \%)$ \\
Clinical anemia & 5 & 10 & $15(23.07)$ \\
Rectal bleeding & 1 & 0 & $1(2 \%)$ \\
\hline
\end{tabular}

UG: Gastric Ulcer; UD: Duodenal perforation; UGD: Gastro Duodenal Ulcer.

Table 4. The different clinical forms of PUD.

\begin{tabular}{ccc}
\hline Clinical forms & Frequency & Percentage \\
\hline Duodenal perforation & 2 & 3.1 \\
Gastric perforation & 40 & 61.5 \\
Uncomplicated duodenal ulcer & 11 & 16.9 \\
Uncomplicated gastric ulcer & 4 & 6.2 \\
Hemorrhagic ulcer duodenal & 7 & 10.8 \\
Hemorrhagic ulcer gastric & 1 & 1.5 \\
Total & 65 & 100 \\
\hline
\end{tabular}

\subsection{Paraclinical Aspects}

Gastroscopy was performed in 23 patients or $35.38 \%$ of patients. Duodenal localization was predominant in 18 patients (78.3\%) against five cases $(21.7 \%)$ for gastric localization.

The ulcer was located on the anterior surface of the bulb in eight cases $(34.8 \%)$, on the floor in four cases (17.4\%), on the rear side in four cases $(17.4 \%)$ and the roof in eight cases $(8.7 \%)$. In the stomach, ulcer was located at the prepyloric lair in two cases $(8.7 \%)$, the juxtapylorique lair in two cases $(8.7 \%)$ on the lesser curvature in one case. 
The macroscopic appearance was dominated by oval type in $52.38 \%$ of cases.

It was conducted a sample (biopsy or resection surgical specimens) in 43 patients (66.15\%); histological analysis of the pieces was made in 26 patients. No malignancy was found in our sampling. A case of intestinal metaplasia was found. Inflammatory aspect of the gastric mucosa was found in all patients. The test for Helicobacter pylori was specified in ten patients and was positive in three patients.

\subsection{The Therapeutic Aspects}

The specific medical treatment consisted of the administration of anti-secretory with or without antibiotics. This treatment was retrieved in all patients and especially based on the intravenous administration initially followed by associated per os relay anti secretory or not to antibiotics.

A surgical intervention was performed in all perforations. The intervention consisted of a cutting of banks followed by suturing the breach: gastric (40 patients either $95.23 \%$ ) or duodenal (two patients either $4.76 \%$ ). This practice was completed in all patients with an omentoplasty.

The average hospital stay was 8.2 days with extremes of 3 and 25 days. The Figure 2 shows the distribution of patients according to the evolution during hospitalization.

The main complications were suture line failure ( 1 case) and the parietal suppuration (1 case).

Five patients died during hospitalization (7.7\%).

Among the deceased patients, three $(7.14 \%)$ had perforation. The other deaths were related to the presence of severe comorbidity including primary liver cancer.

The specific rate of perforations mortality rate was 7.14\%.

Complete healing after endoscopic control was observed in 18 patients (72\%). In seven cases $(28 \%)$, control has still found an ulcer.

\section{Discussion}

\subsection{Demographic Aspects}

In our study, the overall prevalence of peptic ulcers was $6.59 \%$. An earlier study by

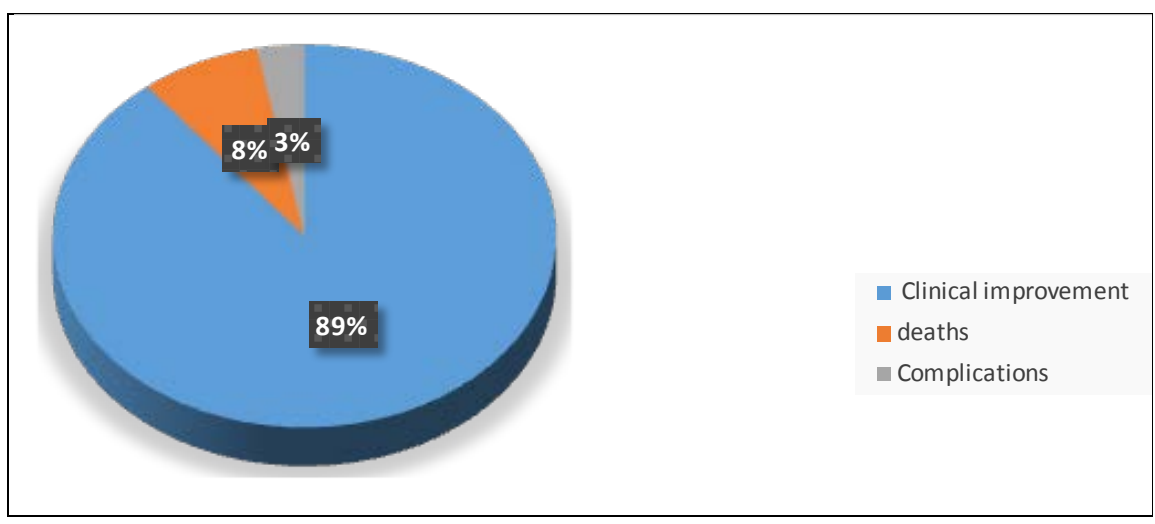

Figure 2. Distribution of patients according to the evolution. 
Millogo [6] in 2010 in the same department reported a prevalence of peptic ulcer of $10.12 \%$. In Africa, the prevalence of PUD reported by the authors is higher. Diarra in Mali [7] Lawson in Togo [8] and Ibara in Brazzaville [9] found respectively 10.80\%, $15.53 \%$ and $30.42 \%$.

In Brazil, Carli DM et al. [10] observed in 10 years a significant decrease in the prevalence of PUD from $30.35 \%$ to $20.19 \%$ associated with a decrease of the prevalence of Helicobacter pylori. Similar results were also observed in Europe. In Spain, M.A Perez et al. reported a steady decline in the incidence of PUD between 1990 and 2000 [4]. The fall of the prevalence of PUD in the United States, Europe and Asia would be associated with the best hygienic conditions related to improving social and health conditions over the years and the systematic eradication of Helicobacter pylori [2] [4] [10]. In Dakar Diouf et al. [11] observed a decrease in the prevalence of PUD from $23.5 \%-24.10 \%$ in 1990 to $12.4 \%$ in 2010 with a decrease in Helicobacter pylori. In Burkina Faso prevalence of PUD decreased from $10.12 \%$ to $6.59 \%$ in 5 years. This decline may be related to the accessibility of IPP and implementation guidelines on the eradication of Helicobacter pylori for practitioners.

New studies on the current prevalence of PUD in other health facilities in Ouagadougou are needed to confirm this downward trend.

The average age of our patients was 40.6 years. Our results confirmed those of other African authors including Millogo [6], Lawson [8], Diarra [7], and Diouf [11] with respectively $43.4,43.56$ years, 43.28 years and 42.5 years. The PUD occurs at a later age in the European than in African one [8].

Our study found male predominance reported by most authors [6] [7] [9] [11] [12].

\subsection{Clinical Aspects}

At the first rank of the gastro-toxic drugs involved in PUD, NSAIDs were found in 53 patients (81.6\%). Of these, $69.8 \%$ showed gastroduodenal perforations and $30.2 \%$ were hospitalized in the Gastroenterology service. This strong association of NSAIDs to PUD especially to acute complications was also reported at $46 \%$ by Ibara [9]. The concern of Non-Steroidal anti-inflammatory in the origin of ulceration is recognized and accepted by all authors [3] [10] [13] [14].

The factors related to tobacco, alcohol and spices were found in respectively $50.8 \%$, 49.2\% and $44.6 \%$ patients. Ibara et al. [9] found tobacco, alcohol and spices in 16\%, $18 \%$ and $37 \%$; while Kadjo et al. [12] in the same way reported 9\%, 12.5\% and 59.5\%. Though regularly cited by the patients, the role of spices as cause of ulceration is not formally established.

The consumption of tobacco and alcohol was observed in our study with great frequency. This finding corroborates the results of many authors who [13] [15] strongly identified alcohol and tobacco poisoning as cause of ulceration.

Gastric localization was 2.25 times more frequent than duodenal in our study. This finding was not found in the literature and was opposed to the results reported by several authors [3] [16]. However, our data are similar to those of Millogo [6] and Traoré 
[17] who found a prevalence of gastric location.

This discrepancy could be explained by the diagnostic confusion between intraoperative duodenal and gastric location that is attributable to the effect of anesthesia; anesthesia could lead to a relaxation and a dilatation of pyloric, important reference that separates the lair of the bulb; this situation makes difficult to assess the boundaries between the pyloric and duodenal bulb. Indeed we found that for the case of PUD confirmed by gastroscopy which is the diagnostic test of reference, the UD/UG ratio (18/5) was comparable to that found in literature. In contrary, the diagnoses made during surgery show a clear predominance of gastric location. More than half of the cases in our study (64.61\%) were diagnosed intraoperative, the trend of our study was therefore determined by this method.

The clinical cases in our study were dominated by complications $76.9 \%$ or 50 cases. In a study conducted in Spain, Perez [4] found $40 \%$ of complicated cases. This difference is due to the method of recruitment. In Perez et al. it was an endoscopic study. The perforations PUD were the most represented with 42 patients (64.6\%). This complication was increase. In an earlier study conducted in 1999 by Traore [17] [18] [19], 40 cases of perforation of PUD were collected over a period of 7 years (January 1992December 1998). Millogo [6] in 2010 found 57.9\% of GD perforation. Self-medication and particularly taking some aggressive gastrointestinal drugs partly explain the importance of ulcer perforations.

Hemorrhagic complications were found in eight patients. This was hematemesis associated to melena in five patients. Ibara [9] in Brazzaville and Lawson in Lome [8] found higher rates $18.14 \%$ and $20.51 \%$ respectively. This difference is probably due to the method of recruitment (endoscopic study).

The specific rate of perforations mortality rate was $7.14 \%$. This specific mortality varies according to different authors: $19.3 \%$ with Gona in Ivory Coast [16], 8.5\% with Kocer in Turkey [15] Age, abdominal sepsis, comorbidity and delayed treatment are risk factors [16].

\section{Conclusion}

PUD rate in hospital increased from $10.12 \%$ to $6.59 \%$ in 5 years. This decline may be related to treatment of Helicobacter pylori eradication commonly prescribed by practitioners. The complications are dominated by stomach perforations with a high specific mortality (7.14\%). These gastric perforations are increase and seem related to NSAIDs. Better management of this disease requires awareness of the population to self-medication.

\section{References}

[1] Groenen, M., Kuipers, E., Hansen, B. and Ouwendijk, R.T. (2009) L'incidence d'ulcères duodénaux et d'ulcères gastriques au sein d'une population occidentale: De retour à la case de départ. Journal Canadien de Gastroenterologie, 23, 604-608.

https://doi.org/10.1155/2009/181059

[2] Diarra, M., Konaté, A., Traoré, C., Soukao, A., Kanate, B. and Diallo, A. (2009) Ulcères ga- 
stroduodénaux en milieu rural au Mali. Mali Medical, 24, 1-3.

[3] Lawson-Ananissoh, L.M., Bouglouga, O., Bagny, A., Yakoubou, R.E.-H., Kaaga, L. and Redah, D. (2015) Profil épidémiologique des ulcères gastro-duodénaux au centre hospitalier et universitaire Campus de Lomé (Togo). Journal Africain d Hépato-Gastroentérologie, 9, 99103. https://doi.org/10.1007/s12157-015-0597-5

[4] Ibara, J.R., Ikourou, A. and Itoua Ngaporo, A. (1993) Les ulcères gastriques et duodénaux à Brazzaville. À propos de 728 cas. Médecine D’ Afrique Noire, 40, 459-465.

[5] Ahsberg, K., Ye, W., Lu, Y., Zheng, Z. and Staël von Holstein, C. (2011) Hospitalisation of and Mortality from Bleeding Peptic Ulcer in Sweden: A Nationwide Time-Trend Analysis. Alimentary Pharmacology \& Therapeutics, 33, 578-584. https://doi.org/10.1007/s12157-015-0597-5

[6] Feinstein, L.B., Holman, R.C., Yorita Christensen, K.L., Steiner, C.A. and Swerdlow, D.L. (2010) Trends in Hospitalizations for Peptic Ulcer Disease, United States, 1998-2005. Emerging Infectious Diseases, 16, 1410-1418. https://doi.org/10.3201/eid1609.091126

[7] Proctor, M.J. and Deans, C. (2014) Complications of Peptic Ulcers. Surgery Oxfam, 32, 599-607.

[8] Pérez-Aisa, M., Del Pino, D., Siles, M. and Lanas, A. (2005) Clinical Trends in Ulcer Diagnosis in a Population with High Prevalence of Helicobacter Pylori Infection. Alimen-tary Pharmacology \& Therapeutics, 21, 65-72. https://doi.org/10.1111/j.1365-2036.2004.02297.x

[9] Malmi, H., Kautiainen, H., Virta, L.J., Färkkilä, N., Koskenpato, J. and Färkkilä, M.A. (2014) Incidence and Complications of Peptic Ulcer Disease Requiring Hospitalisation Have Markedly Decreased in Finland. Alimentary Pharmacology \& Therapeutics, 39, 496506. https://doi.org/10.1111/apt.12620

[10] Millogo, T. (2010) Maladie ulcéreuse gastro-duodénale en hospitalisation au CHU/YO: Aspects épidémiologiques, cliniques et thérapeutiques. Thèse med Ouaga, No. 021, 89 p.

[11] de Carli, D.M., Pires, R.C., Rohde, S.L., Kavalco, C.M. and Fagundes, R.B. (2015) Peptic Ulcer Frequency Differences Related to h. Pylori or Aines. Arquivos de Gastroenterologia, 52, 46-49.

[12] Diouf, M.-L., Ondélé-Ipongo, A.-P., Dia, D., Bassène, M.-L., Mbengue, M. and Seck, A. (2011) Évolution de la prévalence des ulcères gastroduodénaux dans le Centre d'endoscopie Digestive de l'hôpital Aristide-Le-Dantec de Dakar. Journal Africain d Hépato-Gastroentérologie, 5, 23-27. https://doi.org/10.1007/s12157-010-0236-4

[13] Bahmanyar, S., Ye, W., Pickman, P. and Nyren, O. (2007) Long-Term Risk of Gastri Cancer by Subsite in Operated and Unoperated Patients Hospitalized for Peptic Ulcer. The American Journal of Gastroenterology, 102, 1185-1191. https://doi.org/10.1111/j.1572-0241.2007.01161.x

[14] Kadjo, K., Ouattara, B., Sanogo, S., Diallo, A., Adom, A., Yangni-Angate, Y., et al. (1999) Aspects épidémiologiques des ulcères gastro-duodénaux. Médecine d Afrique Noire, 46.

[15] Garrow, D. and Delegge, M.H. (2010) Risk Factors for Gastrointestinal Ulcer Disease in the US Population. Digestive Diseases and Sciences, 55, 66-72. https://doi.org/10.1007/s10620-008-0708-x

[16] Najm, W.I. (2011) Peptic Ulcer Disease. Primary Care: Clinics in Office Practice, 38, 383394. https://doi.org/10.1016/j.pop.2011.05.001

[17] Kocer, B., Surmeli, S., Solak, C., Unal, B., Bozkurt, B., Yildirim, O., et al. (2007) Factors Affecting Mortality and Morbidity in Patients with Peptic Ulcer Perforation. Journal of Gastroenterology and Hepatology, 22, 565-570. 
https://doi.org/10.1111/j.1440-1746.2006.04500.x

[18] Gona, S.K., Alassan, M.K., Marcellin, K.G., Henriette, K.Y., Adama, C., Toussaint, A., et al. (2016) Postoperative Morbidity and Mortality of Perforated Peptic Ulcer: Retrospective Cohort Study of Risk Factors among Black Africans in Côte d'Ivoire. Gastroenterology Research and Practice, 2016, Article ID: 2640730. https://doi.org/10.1155/2016/2640730

[19] Traoré, S.S., Sanou, J., Bonkoungou, G., Kirakoya, B., Zida, M., Bandré, E., et al. (1999) Les perforations des ulcères gastro-duodénaux au Centre hospitalier National Yalgado Ouédraogo de Ouagadougou (Burkina Faso). Revue du CAMES, 1, 39-42.

Submit or recommend next manuscript to SCIRP and we will provide best service for you:

Accepting pre-submission inquiries through Email, Facebook, LinkedIn, Twitter, etc. A wide selection of journals (inclusive of 9 subjects, more than 200 journals)

Providing 24-hour high-quality service

User-friendly online submission system

Fair and swift peer-review system

Efficient typesetting and proofreading procedure

Display of the result of downloads and visits, as well as the number of cited articles

Maximum dissemination of your research work

Submit your manuscript at: http://papersubmission.scirp.org/

Or contact ojgas@scirp.org 